1991

\title{
Am sechsten Sonntag nach Pfingsten
}

\author{
Annette von Droste-Hulshoff
}

\section{Description}

These works within the Sophie Digital Library are a collection of Poetry written by German-speaking women. Within this generic category may be found works such as narrative poems, lyrical poetry, ballads, odes, sonnets and other varieties of poetry, including lyrics designed to be set to music.

Follow this and additional works at: https://scholarsarchive.byu.edu/sophpm_poetry

Part of the German Literature Commons

\section{BYU ScholarsArchive Citation}

Droste-Hulshoff, Annette von, "Am sechsten Sonntag nach Pfingsten" (1991). Poetry. 171.

https://scholarsarchive.byu.edu/sophpm_poetry/171

This Article is brought to you for free and open access by the Poetry and Music at BYU ScholarsArchive. It has been accepted for inclusion in Poetry by an authorized administrator of BYU ScholarsArchive. For more information, please contact scholarsarchive@byu.edu, ellen_amatangelo@byu.edu. 


\section{Am sechsten Sonntag nach Pfingsten (Poem)}

This text comes from a collection of German-speaking women's literature entitled "Deutsche Dichterinnen vom 16. Jahrhundert bis zur Gegenwart: Gedichte und Lebensläufe. Herausgegeben und eingeleitet von Gisela Brinker-Gabler." This text was graciously donated to the Sophie library by Gisela Brinker-Gabler.

Am Sechsten Sonntag Nach Pfingsten

Ev.: Vom Fischfang Petri. Luk. 5, 1-11

Die ganze Nacht hab ich gefischt

Nach einer Perl in meines Herzens Grund

Und nichts gefangen.

Wer hat mein Wesen so gemischt, Daß Will gen Wille steht zu aller Stund

In meiner Brust wie Tauben gegen Schlangen?

Daß ich dir folgen möchte, ach,

Es ist doch wahr, ich darf es sonder Trug

Mir selber sagen!

Was schleicht mir denn gespenstig nach

Und hält wie an den Fittichen den Flug,

Der, auch, zu dir, zu dir mich sollte tragen?

Herr, geh von mir, ich bin ein arm

Und gar zu sündig Wesen; laß mich los,

Ach, laß mich liegen!

Weiß ich, wovon mein Busen warm?

Ob Sehnens Glut, ob nicht die Drangsal bloß

So heiß und zitternd läßt die Pulse fliegen?

Wenn sich auch die Sünde selber schlägt, Wenn aus der Not nach Rettung Sehnen keimt, Ist das die Reue?

Hast du den Richter doch gelegt

In unser Blut, das gen die Sünde schäumt,

Daß es vom wüsten Schlamme sich befreie.

Dies Winden, jedem zuerkannt, Wo irgend noch ein Lebendsodem steigt, Wird es mir frommen?

$\mathrm{Ja}$, als verlöscht der Sonne Brand,

So hat Ägypten sich vor dir gebeugt,

Und seine Sünde ward ihm nicht genommen.

Und has Gewissens Stachel du

Mir auch vielleicht geschärts als andern mehr:

Ich werd es büßen,

Dringt nicht der rechte Stich hinzu,

Der Freiheit gibt dem warmen, reinen Meer,

Daraus die echten Reuetränen fließen.

O eine echte Perle nur 
Aus meiner Augen übersteintem Quell, Sie wär ein Segen!

Du Meister jeglicher Natur,

Brich ein, du Retter, lös die Ströme hell!

Ich kann ja ohne dich mich nimmer regen.

Du, der gesprochen: Fürcht dich nicht!

So laß mich denn vertraun auf deine Hand

Und nicht ermüden.

Ja, auf dein Wort, mein Hoffnungslicht,

Will werfen ich das Netz. - Ach, steigt ans Land

Die Perle endlich dann und bringt mir Frieden? 